\title{
The Construction of China's National Image From Transitivity Perspective-A Case Study of Fighting COVID-19: China in Action
}

\author{
Zhencong Liu \\ School of English Language, Culture and Literature, Beijing International Studies University, China \\ Hui Liu \\ School of English Language, Culture and Literature, Beijing International Studies University, China
}

\begin{abstract}
Using the theory of transitivity system within Systemic Functional Linguistics as the theoretical basis and the white paper named Fighting COVID-19: China in Action, which was published by the Chinese government on June 7, 2020 as the corpus, with the help of corpus analysis tool, UAM Corus Tool 3, this paper uses a combination of qualitative and quantitative methods to explore the construction of China's national image. The results show that the frequency of material processes is extremely high, which is $88.26 \%$, while existential processes and behavioral processes occupy only an extremely small proportion, $0.73 \%$ and $0.09 \%$ respectively. Relational processes are in the second rank, 5.34\%. The frequencies of verbal processes and mental processes are similar, accounting for $2.97 \%$ and $2.6 \%$ respectively. Through a detailed analysis of the six transitivity processes, a national image that advocates "people supremacy", selfless collectivism, with strong executive ability and mobilization, and a great responsibility in the international society is found to be constructed. This paper lays a foundation for further studying China's national image in the path of SFL. It also sheds some light on the construction of China's image in the official government document.
\end{abstract}

Index Term $s$-national image construction, transitivity system, Covid-19

\section{INTRODUCTION}

The prevalence of Covid-19 is a major public health crisis today and a major test of international cooperation and governance. The lives and safety of people and the values and beliefs of humankind are under great threat. Since the outbreak, China has conducted exchanges and cooperation with the international community, enhanced communication, shared information on the outbreak, carried out scientific research cooperation, provided assistance to international organizations and other countries within its capacity, and contributed Chinese wisdom and strength to the global fight against the pandemic. The publication of the white paper Fighting COVID-19: China in Action is a true portrayal of China's arduous course in fighting against pandemic diseases, presenting the image of China as a responsible country that gathers people of all ethnic groups together to get through hard times.

National image, the name card for foreign exchange, is of great significance to enhance national competitiveness and promote international cooperation and development. The construction of the national image is a common task faced by all countries under the background of globalization. The increasingly clear image of "global village" has enabled the international public to pay more attention to, maintain, and enhance the national image from a global perspective. Researches have been conducted to illustrate the concept of national image; however, there is not a definitive and united definition of it due to different research perspectives and fields, such as journalism and communication (Xu, 1996; Wendt, 1999), international politics and economics (Schooler, 1965; Wang, 2013) etc. Boulding (1959) took the leading role in clarifying the relationship between national images and international systems. He holds that "The images which are important in international systems are those which a nation has of itself and of those other bodies in the system which constitute its international environment." In his view, "a nation is some complexity of the images of the persons who contemplate it," roughly including the image of the small group of powerful people, and the image of the mass of ordinary people. Nye (2004)'s opinion regarding the national image as a kind of soft power, which refers to the charm of a country's culture, political system, and values, influences a great deal of research afterward. He mainly discussed the influence of the national image on the construction of a country's political and economic image. Xu (1996) considered that "the national image is the image of a country formed in the international news flow or the image of a country in the news reports of other countries." Guan (2000) defined the national image as "a complex of multi-level images, and it is the general evaluation and recognition of the state itself, its behavior, its activities and achievements by the external and internal public. With great influence and cohesion, it is the embodiment of the country's overall strength." There is no doubt that the construction of the national image could play a significant role in political, diplomatic, and commercial exchanges with other countries in the world.

Today, China is involved in more and more international affairs. China's national image has become a name card in 
foreign relations. A good national image is conducive to the realization of national interests and the promotion of comprehensive national strength. Therefore, how to actively establish and disseminate China's national image in the world has become an important issue for China. In the context of the prevention and control of Covid-19, how to build a responsible China's image is more necessary and urgent than ever. The White Paper, "Fighting COVID-19: China in Action" is an important document that truly records the arduous course of China's fight against the pandemic. Through it, Chinese people's experiences are recorded in detail, the experience and practice of China's fight against pandemic diseases are shared with the international community, and the Chinese concept and propositions of the global fight against pandemic diseases are expounded. As the most official document presented to the international world, studying how and what national images are constructed it is of great practical importance. In today's era of global information explosion, in response to Western countries' false reports and stigmatization of China's national image, although efforts have been made to spread Chinese words and voice and present the real image of China to the world, we still have a long way to go. Thus, this paper could provide some practical suggestions on constructing China's national image from the perspective of the use transitivity system, which is also a brand-new angle.

\section{THEORETICAL BASIS}

Transitivity system, as a semantic system, is a representation of the experiential function of ideational metafunction proposed by Halliday (1994), the founder of systemic functional linguistics. From the perspective of functional grammar, all cultures in language reflect some universal metafunctions: the ideational function, the interpersonal function, and the textual function. The ideational function can be further divided into the experiential function and the logical function.

According to different language use, these functions can be divided into several semantic functions and their corresponding sub-systems. For example, the ideational function consists of the transitivity system, the voice system, and the polarity system; the interpersonal function includes the mood system, the modality system, and the key system; the text function includes the theme system, the information system, and the cohesion system, etc.

Transitivity is the main content of the ideational function, which is the realization and representation of the real world and the inner world of the language users. Halliday (1994) proposed that a process-centered theoretical framework should be established to understand experience through the transitivity system, which contains three transitivity components: the process itself, participants in the process, and circumstances associated with the process.

As the central concept of transitivity system, processes are categorized into six kinds, including three main processes: material processes, mental processes, and relational processes, and three compliment processes: behavioral processes, verbal processes, and existential processes. Material processes are processes of "doing", meaning that some entity does something. There are two participants in material processes; one is called the actor, which does the activity or action; another is called the goal, which is the recipient of the action. Mental processes are processes of sensing, including two participants: senser and phenomenon. There are four sub-categories of mental processes, including perceptive processes, cognitive processes, desiderative processes, and emotive processes. Behavioral processes are almost in the middle between mental and material processes, including physiological and psychological behaviors, such as breathing, coughing, and smiling, etc. Only one participant is included in behavioral processes. Verbal processes are processes of saying, involving three participants: the sayer, which is the speaker; the verbiage, which is the content of the verbal process; and the receiver, to whom the saying is directed. Relational processes are the processes of being, suggesting the relationship between two entities. Relational processes can be classified into attributive and identifying processes. Existential processes stand for the existence of an entity, with the typical words "there" or "exist" at the beginning of a sentence. Figure 1 illustrates the categories of processes intuitively.

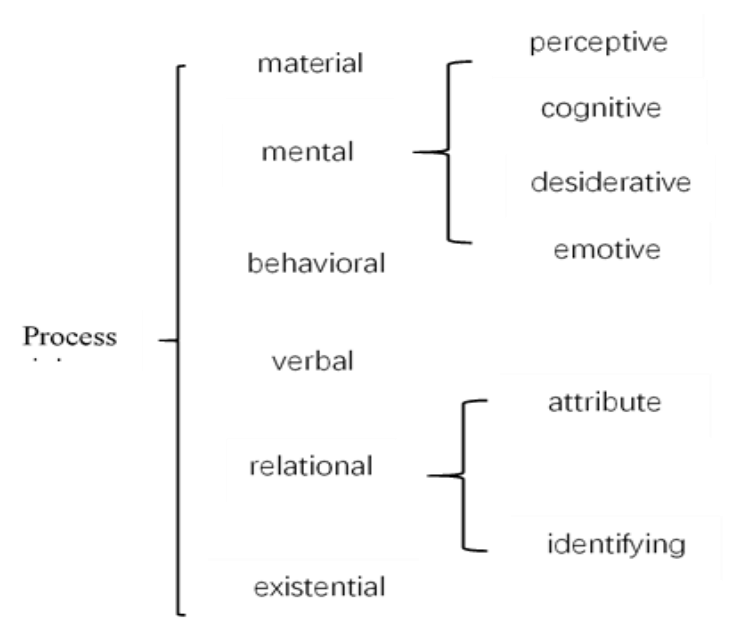

Fig. 1 The Categories of Process in Transitivity System 
Every process has its corresponding participants: actor, goal, scope, recipient, client, and attribute in material processes; senser and phenomenon in mental processes; sayer, verbiage, and receiver in verbal processes; behaver and range in behavioral processes; carrier, attribute, identifier, and the identified in relational processes; and existent in existential processes.

Circumstances are divided into nine categories: extent, location, manner, cause, contingency, accompaniment, role, matter, and angle. Extent can be further divided into distance, duration, and frequency; location consists of place and time; manner contains means, quality, comparison, degree, reason, purpose, and behalf; contingency can be divided into condition, concession, and default; accompaniment consists of comitative and additive; role contains guise and product; and angle consists of source and viewpoint.

In this paper, the transitivity system is adopted as the theoretical framework, and the main focus is on the six processes, with the participants and circumstances as complements. The Transitivity system provides an important basis of semantic representation for studying China's national image construction and enhances the reasons and basis of a nation's image construction.

\section{RESEARCH DESIGN}

\section{A. Research Data}

This paper takes the white paper Fighting COVID-19: China in Action as the corpus. On June 7, 2020, the State Council Information Office published the White Paper "Fighting COVID-19: China in Action". It is a true record of the arduous course of China's fight against the pandemic, with a total number of about 23, 000, including the preface, the body, and the conclusion. The body part is divided into four parts, which are 1) China's fight against the pandemic: a test of fire; 2) well-coordinated prevention, control, and treatment; 3) assembling a powerful force to beat the virus; 4) building a global community of health for all.

\section{B. Research Questions}

Using the theory of transitivity system within Systemic Functional Linguistics as the theoretical basis and the white paper named Fighting COVID-19: China in Action as the corpus, with the help of corpus analysis tool, UAM Corus Tool 3, this paper uses a combination of qualitative and quantitative methods to explore the construction of China's national image to better answer the following questions:

1) What are the distributions and realizations of the transitivity processes in the corpus?

2) What are the functions of the transitivity processes in the corpus in constructing China's national image?

3) What national images of China are constructed through transitivity in the corpus?

\section{Research Methods}

This paper uses the corpus analysis tool UAM Corus Tool 3, to study the distribution and realization of transitivity in the data. Both quantitative and qualitative methods are adopted. The research processes are as followed.

Firstly, the document was downloaded from the official website of China government, saved as a TXT type. After text merging and cleaning, a self-built corpus was built. Based on this corpus, this paper will firstly analyze the overall statistics in the corpus.

Secondly, based on the theoretical framework of the transitivity system within system functional linguistics, the UAM Corpus Tool 3, developed by computational linguist Mick O' Donnell, will be used to annotate the transitivity system in the database. The results that it outputs consist of the general text statistics, feature coding, wording, etc., in the form of charts, graphs, figures, etc. We can get the basic information of the database and the distribution of the six processes. Then, a detailed analysis of the realization of transitivity in each process will be followed to discuss how China's national images are constructed through transitivity.

Finally, the major findings and implications will be summarized in the conclusion part, mainly exploring what national images are constructed in the white paper.

\section{RESUlts AND DisCUSSION}

The paper analyzes the language features and realizations of the transitivity system of the white paper, named Fighting COVID-19: China in Action to explore the construction of China's national image through micro-linguistics facts. This part will show the distributions and realizations of the transitivity with quantitative and qualitative approaches.

\section{A. The General Statistics of Research Data}

Based on the self-built corpus, the basis textual characteristics of the data are shown in table 1 with the help of UAM Corus Tool 3. Overall, the length of the corpus is 23,083 words, and 911 sentences in the text. The average word length is 5.52, and the average sentence length is 25.3. The types and tokens of the corpus are 3,076 and 23,449 respectively, and the type/token ratio of the corpus is $13 \%$. 
TABLE. 1

THE GENERAL TEXTUAL CHARACTERISTICS IN THE CORPUS

\begin{tabular}{|c|c|c|}
\hline Term & Specifics & Statistics \\
\hline \multirow{5}{*}{ Text Complexity } & Av. Word Length (chars) & 5.57 \\
\hline & Av. Word Length (syllables) & 2.38 \\
\hline & Av. Segment Length (tokens) & 6.81 \\
\hline & Min. Segment Length (tokens) & 1 \\
\hline & Max. Segment Length (tokens) & 55 \\
\hline \multirow{2}{*}{ Lexical Density } & Lexemes per segment & 4.18 \\
\hline & Lexemes $\%$ of text & $61.36 \%$ \\
\hline \multirow{2}{*}{ Subjectivity } & Subjective Positivity & 0.117 \\
\hline & Subjective Strength & 0.243 \\
\hline \multirow{3}{*}{ Reference Density } & 1p Reference & $0.186 \%$ \\
\hline & $2 \mathrm{p}$ Reference & $0.000 \%$ \\
\hline & 3p Reference & $1.813 \%$ \\
\hline
\end{tabular}

\section{B. Distributions of the Transitivity Processes}

Table 2 provides a clear distribution and the percentage of the six processes. A total of 2,189 ranking clauses are found in the corpus. Material processes occur predominantly with $88.26 \%$. Then in the second rank are relational processes, accounting for $5.34 \%$. Verbal processes and mental processes take the next place, with $2.97 \%$ and $2.60 \%$. Existential processes have a proportion of $0.73 \%$. Behavioral processes account for the smallest proportion, with $0.09 \%$.

TABLE. 2

Distributions OF THE SiX TRANSITIVITY PROCESSES IN THE CORPUS

\begin{tabular}{ccc}
\hline Process Type & Frequency & Percentage \\
\hline Material & 1932 & $88.26 \%$ \\
Relational & 117 & $5.34 \%$ \\
Mental & 65 & $2.97 \%$ \\
Verbal & 57 & $2.60 \%$ \\
Existential & 16 & $0.73 \%$ \\
Behavioral & 2 & $0.09 \%$ \\
Total number & 2189 & $100 \%$ \\
\hline
\end{tabular}

As shown from table 2, the frequency of material processes is extremely high, while existential processes and behavioral processes occupy an extremely small percentage. The frequencies of relational process, verbal process, and mental process are basically the same. The distribution characteristics are determined by the type of the data, which is an official government document. A detailed discussion will be made in the next part.

1. The realizations and functions of material processes

Material processes are mainly used to describe some concrete behaviors or actions in the real world, in which the main participants include the actor, the goal, the recipient, and the scope. Material processes describe objective facts or situations, giving readers a sense of authenticity, which is also the main feature of an official government white paper. Thus, these are the highly used processes in the corpus. The realizations of material processes are achieved through some high-frequency words, the top ten words in frequency are: "made" (54 times), "released" (33 times), "chaired" (25 times), "held" (22 times), "taken" (22 times), "provided" (19 times), “adopted" (18 times), "issued" (18 times), "prevented" (15 times), "mobilized" (13 times). It can be seen that most material process words are used to describe the efforts China has made to fight against Covid-19. Following are some examples of material processes.

Example 1: Government departments have made well-coordinated control efforts.

Example 2: General Secretary Xi Jinping has taken personal command.

Example 3: China has provided support for global virus prevention and control by promptly sharing information and experience with the international community.

Example 4: Trade unions, Communist Youth League organizations, women's federations, and other mass organizations organized and mobilized their contacts among the general public to get involved in Covid-19 prevention and control.

Example 5: The NHC released Diagnosis and Treatment Protocol for Covid-19 (Trial Version 6).

Example 6: Xi Jinping has chaired 14 meetings of the Standing Committee of the Political Bureau of the CPC Central Committee.

From the perspective of the actor and the recipient, "China" and "Xi Jinping" are the most frequent actors, which emphasizes that CPC and the Chinese government have made great efforts in virus prevention and control under the leadership of general secretary Xi Jinping with an impression of caring for the people. In example 4, many actors are involved in Covid-19 prevention and control, demonstrating Chinese peoples' solidarity and unanimity. While facing the common challenges, all strengths from all sectors of the community make their contribution. It should also be noted that, besides the Chinese society and Chinese people, there is one participant as the recipients in material processes that cannot be overlooked, the international community. Since the outbreak of the pandemic, China has vigorously advocated and advanced international cooperation, provided strong support to other countries in responding to the pandemic, and fully demonstrated its responsibility as a major country. 
2. The realizations and functions of relational processes

Relational processes are the processes of being, suggesting the relationship between two entities, emphasizing the circumstances in which entities are located and the connections between entities. Relational processes can be classified into attributive and identifying types. Some examples representing relational processes are as followed.

Example 7: The Covid-19 global pandemic is the most extensive to afflict humanity in a century.

Example 8: Solidarity and cooperation are the most powerful weapons available to the international community in the war against the pandemic.

Example 9: After weathering the pandemic, the Chinese people have keenly realized that the CPC leadership is the most reliable shelter against storms.

Example 7 belongs to the attributive mode, indicating the seriousness and harmfulness of Covid-19; thus, prompt and effective actions against the pandemic are of no delay time. Examples 8 and 9 belong to the identifying mode. In example 8, power weapons are used to identify solidarity and cooperation of the international community, demonstrating China's emphasis on solidarity, communication, and solidarity. It is a good example to prove the correctness of the concept of a community with a shared future for mankind. Example 9 shows Chinese people's trust in the CPC leadership in the war against the pandemic.

3. The realizations and functions of mental processes

Mental processes are processes of sensing, including two participants: senser and phenomenon. The official report is expected to avoid using too many mental processes since they reflect the subjective cognitive to ensure the objective and authenticity. However, the importance of mental processes should not be overlooked. Proper use of mental processes can express positions and opinions strongly and powerfully, conveying a confident and convincing image to readers. Some examples are as followed.

Example 10: When the novel coronavirus struck, China decided that it would protect the lives and health of its people even at the cost of a short-term economic downturn and even a temporary shutdown.

Example 11: China firmly believes that as long as all countries unite and cooperate to mount a collective response, the international community will succeed in overcoming the pandemic, and will emerge from this dark moment in human history into a brighter future.

Example 12: The WHO-China Joint Mission on Covid-19 held a press conference in Beijing, during which team members agreed that China had achieved notable success in slowing the spread of the virus and blocking human-to-human transmission, at least delaying, and possibly preventing hundreds of thousands of infections.

All these examples here express an obvious positive attitude tendency. The first two examples take China itself as the starting point, showing China's deep concern for people's safety and health and a clarion call for international cooperation to fight against Covid-19 together, and showing the world that China is a peace-loving justice force. The third example takes a third person's angle, indirectly affirming China's actions and efforts.

4. The realizations and functions of verbal processes

Verbal processes mainly refer to the process of transmitting and communicating information. The primary participants are the sayer, the receiver, and the verbiage, which represents the content of the verbal process. Verbal processes can be realized by direct and indirect quotations. Verbal processes are seldom used in the report, which is a feature of general political discourse to avoid excessive subjectivity. The main words that are used in the corpus, fulfilling the function of verbal processes, are emphasized (13 times), said (10 times), announced (5 times), stressed (3 times). Examples extracted from the corpus are as followed.

Example 13: He (President Xi Jinping) emphasized that people's lives and health must come first and resolute efforts should be taken to stem the spread of the virus.

Example 14: He (President Xi Jinping) said, "The virus is a devil, and we must hunt it down. The Chinese government has been providing timely updates on the pandemic in an open, transparent, and responsible way. We have responded to the concerns of various parties and enhanced cooperation with the international community."

Example 15: The president said that biosecurity should be an important part of the holistic approach to national security.

Example 16: WHO Director General Tedros Adhanom Ghebreyesus announced, "We have therefore made the assessment that Covid-19 can be characterized as a pandemic."

The sayers in verbal processes in an official government document are people who have significant influence in politics, the economy, or some other aspects that needed to be selected scrupulously. The information is always held by government officials or authoritative scholars, making the report more convincing and authentic. Examples 13. 14, 15 are verbal processes, whose sayer is President Xi Jinping. What he said demonstrates the people-centered value and thought, and the morality of serving the people heart and soul. The information that China will always give priority to the safety and health of the public's life. Additionally, China has always adhered to the concept of a community of shared future for mankind, providing assistance to other countries within its ability and enhancing cooperation with the international community. In Example 16, an official of WHO's words have been quoted to emphasize the severity of the pandemic, thus, fighting against is of great urgency.

5. The realizations and functions of existential processes

Existential processes are mainly used to describe the existence of people or things, and the main participants are 
beings. Existential processes clauses only indicate the objective existence of things or people, which can enhance the authenticity and credibility of the reports. This type accounts for a very low percentage, and the form of "there be" is the only realization in the corpus. Some examples are presented as followed.

Example 17: From March 1 to May 31, China exported protective materials to 200 countries and regions, among which there were more than 70.6 billion masks, 340 million protective suits, 115 million pairs of goggles, 96,700 ventilators, 225 million test kits, and 40.29 million infrared thermometers.

Example 18: There was a severe shortage of hospital beds in the early stage as the number of infections surged.

Example 19: There are multiple deficiencies in current global health governance, including the absence of an international mechanism for joint prevention and control of infectious diseases and a dire shortage of international public health resources.

The main function of existential processed is to describe reality and facts objectively. By using the existential process phrase, "there were" and a series of numbers, Example 17 states China's contributions in a moderate but detached way, making the statement more impersonal and easier to accept. While Examples 18 and 19 describe the real situations from a negative perspective, which is accepted in a government report. The official government document cannot merely report the positive and beneficial news. On the other hand, the presentation of some real situations, although it can be frustrating, can earn people's more respect and trust. Moreover, it is natural and necessary.

6. The realizations and functions of behavioral processes

Behavioral processes usually include physiological and psychological behavior, such as breathing, coughing, and smiling, etc. Only one participant is included in the behavioral processes. However, in political discourse, behavioral processes are rarely used. There are only two clauses in the corpus. One typical example is presented in the following.

Example 20: He (President Xi Jinping) also talked by video link to doctors from Wuhan Jinyintan Hospital, Wuhan Union Hospital, and Huoshenshan Hospital where novel coronavirus patients were being treated.

Behavioral processes clauses regularly feature a prepositional phrase, such as "talk to" in Example 20. President Xi Jinping expresses a deep concern to the patients, representing the country always puts people in the first place.

\section{CONCLUSION}

According to the results and discussions above, it can be seen that all the six process types are included in the corpus with different frequencies. Material processes account for the largest proportion with $88.26 \%$ of all the clauses, followed by relational processes with $5.34 \%$. The frequencies of verbal processes, and mental processes are basically the same, account for $2.97 \%$ and $2.6 \%$ respectively. While existential processes and behavioral processes are only $0.73 \%$ and $0.09 \%$ respectively.

As for the different processes, typical words and phrases with specific characteristics are utilized to fulfill various functions, which are the realizations of the transitivity system. As the semantic features, the transitivity system can fully use its rigorous and comprehensive advantages to connect the external world, better explaining the physical world. After the detailed analysis in part IV, the question, what national images of China are constructed through transitivity in the corpus can be answered. Overall, three images are constructed in the corpus.

Firstly, from the perspective of values and philosophy, a national image that advocates "people supremacy", selfless collectivism with national unity and harmony, is constructed. Throughout the pandemic prevention and control, China has always adhered to the principle of "People first, life first" and has worked out major strategic measures in the light of the situations and circumstances. Thus, the fight against the pandemic can be in an efficient and orderly manner. In the face of the pandemic, the Chinese people have braved hardships and dangers and rallied as one. The whole country has acted in unison, and all sectors of society have made concerted efforts. This image can be seen through almost all six transitivity processes, especially in the material processes, verbal processes, and mental processes, where information can be conveyed both in objective and subjective tendency.

Secondly, from the perspective of action, a national image with strong executive ability and mobilization is constructed. After the outbreak, under the personal command and deployment of general secretary Xi Jinping, all localities have launched the first-level response mechanism for major public health emergencies. Huoshenshan Hospital and Leishen Hospital were built and put into use in a few days. A mechanism for joint prevention and control was quickly established nationwide to bring the pandemic under effective control.

Thirdly, from the perspective of international contributions, a national image of great responsibility is constructed. Through the analysis of material processes, relational processes, mental processes, and verbal processes, we can see that China calls for solidarity and cooperation and communicates and cooperates with the international community, assisting international organizations and other countries and contributing Chinese wisdom and strength to the global fight against the pandemic.

All in all, China's image in the white paper, Fight against Covid-19, China in Action, is constructed objectively and truly in terms of transitivity. The method used in this paper lays a foundation for the further study of China's national image in path of SFL. It also can provide some references for the construction of China's image in the official government document. 


\section{REFERENCES}

[1] Boulding, K. E. (1959). National images and international systems. Journal of conflict resolution, 3(2), 120-131.

[2] Guan Wenhu. (2000). Theory of national image. Chendu: The University of Electronic Science and Technology Press.

[3] Halliday, M. A. K. (1994). An introduction to functional grammar. London: Edward Arnold.

[4] Nye Jr, J. S. (2004). Soft power and American foreign policy. Political science quarterly, 119(2), 255-270.

[5] Schooler, R. D. (1965). Product bias in the Central American common market. Journal of Marketing Research, 2(4), 394-397.

[6] Wang Haizhou. (2013). The Knowledge Graph of the Study of National Image and Its Political Turn. Cass Journal of Political Science, (03), 3-16.

[7] Wendt, A. (1999). Social theory of international politics (Vol. 67). London: Cambridge University Press.

[8] Xu Xiaoge. (1996). National Image in international news communication. Journalism \& Communication, (02), 35-45.

[9] Zhang Yuqiang. (2002). On national image. Modem Communication, (02), 27-31.

Zhencong Liu is currently Associate Professor in the School of English Language, Culture, and Literature, Beijing International Studies University, China. He received his PH.D degree in linguistics from Beijing Foreign Studies University, China in 2007. His research interests include general linguistics, cognitive linguistics, language teaching and research. Dr. Liu has published more than 11 textbooks and 30 research papers on cognitive and applied linguistics.

Hui Liu (corresponding author) was born in Hebei province, China in 1997. She will receive her Master Degree from Beijing International Studies University, China in 2023. Her research interests include second language acquisition, corpus linguistic and English teaching, and discourse analysis. 